\title{
Information Technology and Digitization of Information Media
}

\author{
Hongbing Zhang \\ Normal Police University of China, Shenyang, 110854, China \\ zhbhn@sina.com
}

Keywords: Information Technology; Technology Alienation; Post-modern Technology; Cultural Education

\begin{abstract}
The role of technology is becoming increasingly apparent during the development of education. Development of education has experienced many processes in the history of human social development, which affect the development of information technology to education has brought the most obvious. Further analysis, we find that self-education after independence from society, IT involvement is always a profound influence on the development of education and direction. The development of modern information technology, the technology practices into education, provide a lot of convenience, but also provide the conditions for the field of education technology alienation, to make education from the real practice. Education is moving away from the humanistic philosophy in the role of modern information technology, the post-modern technology, as solution, brings a possible developing direction to education.
\end{abstract}

\section{Introduction}

Impact of information technology on human society gradually manifest in the field of education, but also increasingly profound. For example, the installation of cameras to monitor teachers and students teaching and learning in the classroom, using fingerprint identification system, electronic attendance system to control the whereabouts of students and teachers, substitute teachers use a variety of teaching systems, and so on. Recalling the history of the development of education, study the role and impact of technology in education development, mastery of technology applied to the internal laws of education, is one possible way to solve the technical problem of alienation.

Some scholars believe that education is the history of the development of human technology to intervene and influence the history of education, and proposed development in the history of education were a total of four times larger revolution in education. The first stems from the development of the social division of labor productivity caused by education of the younger generation's task will be followed by the parents began to turn to teachers, family-shift schools. Specializing in educational activities appeared to produce teachers and schools are this educational revolution flag, it means that educational activities have been independent from social life, systematic education produced. The second began in the produce and widely used text, so writing has become the primary means of education. Prior to this popular teaching language and action, and thereafter began writing and speaking the language coexist in the educational process. The third stems from the invention of printing and paper and succeeded by the emergence of a large number of books, which is to move toward universal school education, is an important foundation and prerequisite. Fourth from the impact of electronic technology and information society, especially audio-visual technology and computer technology flock to the field of education and psychology experts, behavioral science and other aspects of this revolution added that the impact of this revolution changed the traditional education a more extensive and in-depth. The current computer and network at the core of modern information technology in the information store, said the transfer, handling and so on have undergone enormous changes, the impact on education not only to represent the external media use and teaching of information and communication on the way, but also the inherent performance in educational theory, teaching methods, teaching mode, teaching methods, and its profound and widespread impact. 


\section{Effects of information technology on Education}

Information and Education Practice. Close contact with the great development of education and information technology revolution between the existences of such a link is also available from the inherent nature of education and practice of characterization to obtain evidence. "Education is a human-specific genetic and communication methods, the reproduction of human beings and the re-creation." Xinmin Sang at the same time raise this awareness, but also on educational activities conducted in-depth investigation, believes education is the common understanding and practice, education is "informative practice" and that the "information-type practices" and "matter-energy type practice" has a fundamental difference. "Material and energy-based practice" consumption and output are appropriate matter and energy, "Information-type practice" is different, although there will be a material and energy consumption, but not in substance and energy output for the ultimate goal , matter and energy are consumed in the process of information activities, the aim is to change the status of the role of information objects. It is this type of educational practice information, material and energy consumption in almost all of the teaching and learning of information collection, storage, presentation, presentation, transmission, processing and other information activities in the process, so that the information activities become the centre of the work of educational practice, it will thus become the key technology education practice course.

Synchronous development of information and education. Further analysis, we find that self-education after independence from society, IT involvement is always a profound influence on the development of education and direction. Educational purpose, from the "original rich" to the separation and practice, from the logic of the text which dominates the logic of the text and images to the practice of leaving the coexistence return possible; education scale, from the minority to the majority of patent civilians, to universal education for all; education, from poly-only lectures, independent reading dilemma to standardize class system, to the variety of ways possible. These changes are all education reveals the value of information technology.

\section{Post-modern technology and education in the new development}

When the technology to "Modern IT" stage after its alienation nature also beginning to emerge, the previously mentioned concentration phenomenon is evidenced in the field of education, and to solve technical alienation of the people an alternative to negative, coercion, control and indifference after modern technology is a possible way. The basic idea of the post-modern technology is the third stage of technological development. It emphasizes the inheritance and development of technological advantages of modern technology and its "internalized" as the main premise of the nature of power, to maintain its subjectivity, which to some extent digestion alienation of modern technology. Here the "internalization" does not refer to technology must be integrated into the human body, but to combine technology and human mutual entity under the premise of maintaining human subjectivity, the proper division of labour, combining people and technology combine to become high-tech and high-humanities.

After the high-tech modern technology can maintain the advantages of modern information technology, but also to educate the initiative firmly in the grasp of the technical activities of the body in the hands of education, while enhancing educational body strength without losing the essence of subjectivity, which is people on the current and future development in the field of education of modern it requirements. Thus, the future of modern technology-based education will become the future development of education in the current trend.

Digitization and Cultural Education. Popular in the field of education technology tools on values is clearly lagging behind, technology is not just for the value of education as a tool can be explained, it shapes the entire educational environment, affecting all aspects of education. Alienation of modern information technology in the field of education has been quite severe, and its development trend should be standardized, guidance, therefore, learn research techniques philosophy, discard the old technical values, the law of development of educational needs and technology 
development in the field of education as a technology trend the guiding principle is an inevitable choice for the moment. High-tech, low-humanistic modern IT in higher education humanities demand should strengthen the humane care and technology, in accordance with the laws of technological development, to high-tech and high humanistic postmodern technological development. Technology to create the entire educational environment and, ultimately, the power of education is reflected in the nature of the subject among the technology development process and therefore should also be emphasized stability and popularity, otherwise the educational environment of instability inevitably affect the ability to play the main practice, which directly affect education quality. So should the principle of "proper development of high-tech, emphasizing the combination of high tech and humanities, and even the development of high technology in the humanities on the basis of high, high-tech and high-tech is not blind to" the development of the field of education technology, the only way can we keep the main subject of education, but also inherited modern information technology to education brings convenience.

Standardization and individualized information dissemination. There is no doubt that the individual is the ultimate ideal of education, talent needs of the information age is a necessary requirement for the development of education. However, due to lack of restrictions caused by the economic level of educational resources, although modern IT for individualized instruction provides a possible development paths, but still do not have the all-round development of individualized education conditions. Also, the development of human society now, education should be public cultural heritage of human civilization has been quite lucrative, which life as a social foundation of knowledge, skills, methods, and much more, every citizen should be mastered, but this part of the comparison appropriate use of standardized education. Therefore, standardization and individualized education should be an appropriate combination, on this basis, then priority to the development of individualized education to meet the needs of personal development. Based on this, the following two tasks would become the basis for the future development of education. First, the use of technology to strengthen the functions of the standardization of school education, the advantages of using technology appropriately designed for fully individualized education, so that the two can be properly combined; Secondly, the educational objectives and educational content of organic restructuring to fit standardized education content and for the content of individual education separated to some extent, to accommodate standardized education and individual combination.

Educational Practice regression. Education and production practices from the start at the first revolution in education, then, the social productive forces have a certain degree of development, only to be spun off from the social production of material and energy type of practice as an information-type practice educational activity. Today, the education from the fact that production practices, has been criticized for the world, people are continuing to explore possible ways to return to education to practice, but because of the social and agricultural production practices industrial society is still a main type of material and energy practice, practice is difficult and informative educational activities integration, suitable route is still being explored. Currently, the arrival of the information age and the logic of the image of being involved in education may provide a new idea. On the one hand, the entire community of practice patterns have changed, not only in the material energy-based, information-type practice share more and more, and even the type of material and energy practices, information campaigns in which role is increasingly important, therefore, the information type practices can directly use the IT platform to support the achievement. The combination of these two make education return to the practice of having the possibility, of course, the possibility of such a possibility and how to achieve still need further study.

Separate teaching media applied teaching, only applies to traditional teaching methods, teachers' ability to use the media by students restrictions on the media and the media itself clips cognitive effectiveness, teaching effect is not satisfactory. The current rapid development of computer networks has spawned a network of media-based teaching methods, the real multimedia network teaching is achieved through the transfer and sharing of teaching online education information resources, carry out teaching in a network environment, enabling students to be fully developed personality can be fruitful cooperative learning, students develop the knowledge to provide a broad 
space. A network media application expands the scope of application of instructional media, promoting the effective dissemination of information and resources classroom teaching.

Reasonable proper application of multimedia network technology for teaching service is the current trend of development of educational information. However, in practical application discovery, network teaching there is often offset teaching objectives, resources; confusion and poor coordination of teaching methods and teaching media phenomenon, and these phenomena affect the efficiency and effectiveness of online teaching. The dominant position of network teaching emphasizes the leading role of teachers and students, students control their own learning process, teachers guide students in the learning process just to help and panelists. Only in-depth understanding of network teaching media features, and the ability to recognize the network as an extension of teaching media and its powerful role in the spread of resources to be able to recognize the difference between a real online media and traditional media, and the effective use of interactive teaching media network optimization classroom teaching, prompting between teachers and students, two-way communication between the students, the use of open networks, sharing the ability of students to use online media to expand the knowledge space.

Instructional media, including a series of hardware and software, in addition to the above considerations, its acquisition and installation costs cannot be ignored. Many compare and choose both a low-cost media for use again, and be able to play its high performance, and is analyzing, selecting a higher realm of teaching media steps. In the actual teaching process, the media should avoid backward teaching mode and teaching method, which uses advanced media apply backward teaching methods, based on classroom needs to assess whether the choice of advanced media, educational resources to eliminate the phenomenon of mixed media used improperly and other issues. Select instructional media needs to consider the various factors, not every condition must be met, we need to do is to carefully analyze, and understand the primary and secondary issues in order to minimize the cost of education, teaching environment, improve teaching efficiency, promote effectively improve teaching quality.

\section{Conclusion}

Development of education has experienced many processes in the history of human social development, which affect the development of information technology to education has brought the most obvious. With the rapid innovations in information technology, human education increasingly rely on information technology, it is also getting away from the education of the human mind, that is humanistic philosophy of education. The development of modern information technology, the technology practices into education, provide a lot of convenience, but also provide the conditions for the field of education technology alienation, to make education from the real practice. After modern technology, emphasizing the combination of technical education and human education, the importance of standardized and individualized education coexist development, so that the educational practice to achieve a real return to counteract this alienation adverse human education effect may be provided, but also for the information technology development and harmony of modern education and healthy development provides a new direction.

\section{References}

[1] Sang Xinmin. Call for the educational philosophy of new century[M]. Beijing: Education Science Press, 1993.

[2] Guo Chongchen. Theory of technical alienation[M]. Shenyang: Northeastern University Press, 2004.

[3] The Alienation and Its Alleviation of Modern Informational Technology[J]. Modern Education Technology, NO.1.2009. 